\section{FRI0207 THE INCORPORATION OF THE ANTERO-POSTERIOR LUMBAR SPINE VIEW IN THE MODIFIED STOKE ANKYLOSING SPONDYLITIS SPINE SCOREONLY MARGINALLY IMPROVES DETECTION OF RADIOGRAPHIC SPINAL PROGRESSION IN AXIAL SPONDYLOARTHRITIS}

M. Llop ${ }^{1}$, V. Rios Rodriguez ${ }^{1}$, J. Sieper ${ }^{1}$, H. Haibel ${ }^{1}$, M. Rudwaleit ${ }^{2}$, D. Poddubnyy ${ }^{1,3}$. ${ }^{1}$ Rheumatology, Charité Universitätsmedizin, Berlin; ${ }^{2}$ Internal Medicine and Rheumatology, Klinikum Bielefeld Rosenhöhe, Bielefeld; ${ }^{3}$ German Rheumatism Research Centre, Berlin, Germany

Background: The modified Stoke Ankylosing Spondylitis Spine Score (mSASSS) is considered currently as a gold standard of assessment of structural damage in the spine in patients with axial spondyloarthritis (axSpA). However, mSASSS takes into account only structural damage visible on lateral radiographs of the cervical and lumbar spine. Antero-posterior (AP) views might be able to detect structural damage not visible on lateral ones.

Objectives: To evaluate the performance of the extended mSASSS score including AP lumbar radiographs compared to the conventional mSASSS in detection of radiographic spinal progression in patients with axSpA.

Methods: A total of 210 patients with axSpA, 115 with ankylosing spondylitis and 95 with non-radiographic axSpA, from the GErman SPondyloarthritis Inception Cohort (GESPIC) were included in the analysis based on the availability of spinal radiographs (cervical spine lateral view, lumbar spine lateral and AP views), at baseline and year 2 . Two trained readers independently scored lateral cervical and lumbar spine images according to the mSASSS system (0-72). In addition, left and right, upper and lower vertebral corners of vertebral bodies visible on lumbar AP radiographs (lower Th12 to upper S1) were assessed according to the same scoring system ranging from 0 (no abnormality) to 3 (bridging syndesmophyte). Thus, the extended mSASSS had a total range from 0 to 144 . The reliability and the sensitivity to detect radiographic spinal progression of the extended mSASSS as compared to the conventional mSASSS were evaluated. Following definitions for progression were used: change of the absolute scores, change of $\geq 2$ points, development of new syndesmophytes, and development of new syndesmophytes or growth of the existing syndesmophytes after 2 years.

Results: The reliability of both scores was excellent with intraclass correlation coefficients (ICCs) of 0.927 and 0.926 at baseline and 0.933 and 0.920 at year 2 for the extended and conventional mSASSS, respectively. The mean \pm SD score at baseline was $4.25 \pm 8.32$ and $8.59 \pm 17.96$ for mSASSS and extended mSASSS, respectively. The change score between baseline and year 2 was $0.73 \pm 2.34$ and $1.19 \pm 3.73$ for mSASSS and extended mSASSS, respectively (table 1). With the extended mSASSS score as compared to the conventional one, new syndesmophytes after 2 years were detected in 4 additional patients (1.9\%), new syndesmophytes or progression of existing syndesmophytes - in 5 additional patients $(2.4 \%)$, and progression by $\geq 2$ points in the total score - in 14 additional patients $(6.7 \%)$ - table 1 .

Abstract FRI0207 - Table 1. Comparison of the conventional and extended mSASSS for the detection of radiograhic spinal progression in patients with axSpA $(n=210)$

\begin{tabular}{lcc}
\hline & $\begin{array}{c}\text { Conventional } \\
\text { mSASSS } \\
\text { (range 0-72) }\end{array}$ & $\begin{array}{c}\text { Extended } \\
\text { mSASSS } \\
\text { (range 0-144) }\end{array}$ \\
\hline Mean score at baseline, mean \pm SD & $4.2 \pm 8.3$ & $8.5 \pm 17.9$ \\
\hline Mean score at year 2, mean $\mathbf{S D}$ & $4.9 \pm 9.5$ & $9.7 \pm 20$ \\
\hline Mean change score, mean \pm SD & $0.7 \pm 2.3$ & $1.1 \pm 3.7$ \\
\hline Smallest detectable change & 2.9 & 4.5 \\
\hline Standardized response mean & 0.3 & 0.3 \\
\hline Change of $\geq 2$ units, $\mathbf{n}(\%)$ & $30(14.3)$ & $44(21)$ \\
\hline Total number of syndesmophytes at baseline, mean \pm SD & $0.9 \pm 2.6$ & $1.9 \pm 5.2$ \\
\hline Total number of syndesmophytes at year 2, mean \pm SD & $1.1 \pm 3.0$ & $2.2 \pm 5.9$ \\
Development of new syndesmophytes, $\mathbf{n}(\%)$ & $16(7.6)$ & $20(9.5)$ \\
\hline Development or progression of syndesmophytes, $\mathbf{n}(\%)$ & $18(8.6)$ & $23(11)$ \\
\hline
\end{tabular}

mSASSS, modified Stoke Ankylosing Spondylitis Spinal Score

Conclusions: The incorporation of the AP radiographs of the lumbar spine in the assessment of structural spinal damage provided only a relatively small improvement of detection of radiographic spinal progression in axSpA.

Acknowledgements: GESPIC was financially supported by the German Federal Ministry of Education and Research (BMBF) 2000-2007. 2005-2009 complementary financial support was obtained also from Abbott/Abbvie, Amgen, Centocor, Schering-Plough, and Wyeth. Since 2010 GESPIC is supported by Abbvie. The work of Maria Llop was supported by EULAR Scientific Bursary and by FER Institution (Fundación Española de Reumatología).

Disclosure of Interest: M. Llop: None declared, V. Rios Rodriguez Consultant for: Abbvie, Novartis, J. Sieper Grant/research support from: Abbvie, MSD, Pfizer,
Consultant for: Abbvie, MSD, Pfizer, UCB, H. Haibel: None declared, M. Rudwaleit Consultant for: Abbvie, MSD, Pfizer, UCB, D. Poddubnyy Grant/research support from: Abbvie, MSD, Novartis, Consultant for: Abbvie, BMS, MSD, Novartis Pfizer, UCB, Speakers bureau: Abbvie, BMS, Janssen, MSD, Novartis, Pfizer, Roche, UCB

DOI: 10.1136/annrheumdis-2018-eular.5511

\section{FRI0208 ANKYLOSING SPONDYLITIS QUALITY OF LIFE: DEFINING MINIMAL CLINICALLY IMPORTANT CHANGE}

N. Richard ${ }^{1,2}$, N. Haroon ${ }^{1,2}$, G.A. Tomlinson ${ }^{1,2}$, I. Sari ${ }^{1,2}$, Z. Touma ${ }^{1,2}$, R. D. Inman ${ }^{1,2},{ }^{1}$ University Health Network, ${ }^{2}$ University of Toronto, Toronto, Canada

Background: The Ankylosing Spondylitis Quality of Life (ASQoL) is a readable and simple to complete questionnaire relating to health-related quality of life (HRQoL) in ankylosing spondylitis (AS) and it has been shown to be a reliable and valid outcome measure[.' Despite that this tool was used in various research settings over the last decade, the Minimal Clinically Important Difference (MCID) remains to be defined.

Objectives: Our objective is to define the MCID of ASQoL in subjects with axial spondyloarthritis(axSpA).

Methods: All subjects seen at the Spondylitis Clinic of the Toronto Western Hospital between July 2003 and January 2018 with a diagnosis of axSpA [AS or nonradiographic axSpA (nr-axSpA)] were included in this study. The ASQoL comprises 18 questions, and answers are dichotomized into yes/no. The weighted score for each item is 1 and poor HRQoL is associated with higher scores. The Medical Outcomes Study Short Form-36 (SF-36) is an instrument to assess for health status. Subjects completed ASQoL and SF-36 at the same time during yearly visits in the clinic. To determine MCID for ASQoL the SF-36 question 2 (SF36 Q2; "compared to one year ago, how would you rate your health in general now?") was used as an anchor measure. The answer to this question was incorporated in a 5 point Likert scale: "much worse" $(-2$ points), "somewhat worse" -1 point), "about the same"( 0 point), "somewhat better"(+1 point), "much better" +2 points). An important change on the anchor was determined as +2 for improvement and -2 for worsening on the Likert scale. MCID was determined based on the optimal threshold that discriminated between change and no change (improvement or worsening) using receiver operating characteristic (ROC) curve analyses.

Results: A total of 1328 subjects were seen during the follow-up period. Of these $66.2 \%$ were male, $75.3 \%$ were Caucasian, $61.8 \%$ had college or more education and the proportion AS/nr-axSpA was $84 \% / 16 \%$. At baseline, the mean age was 38.7 years and the mean disease duration was 14.9 years. On follow-up visit, patients who reported "much worse", "somewhat worse", "about the same", "somewhat better" and "much better" had a mean change in ASQoL of respectively $3.85,1.30,-0.24,-0.94$ and -3.45 (table 1 ). Differences between mean change in ASQoL were statistically significant $(\mathrm{p}<0.02)$. The area under the ROC curve was $0.72(95 \% \mathrm{Cl} 0.66-0.79)$ for subjects who worsened and $0.69(95 \% \mathrm{Cl}$ $0.66-0.72$ ) for those who improved. The ROC curve analyses showed that for thresholds of -2.5 and -3.5 points in deterioration there was a sensitivity/specificity of $0.536 / 0.841$ and $0.474 / 0.890$, respectively. Similarly, cut-offs of +2.5 and +3.5 points in improvement showed a sensitivity/specificity of $0.464 / 0.825$ and $0.389 / 0.883$, respectively.

\begin{tabular}{lcc}
\hline SF-36 Q2 & Mean ASQoL change & Standard deviation \\
\hline Much improved $(+2)$ & -3.45 & 4.98 \\
Somewhat better $(+1)$ & -0.94 & 3.87 \\
About the same $(0)$ & -0.24 & 3.23 \\
Somewhat worse $(-1)$ & 1.30 & 4.20 \\
Much worse $(-2)$ & 3.85 & 4.94 \\
\hline
\end{tabular}

(-2)

3.85

Conclusions: We identified the MCID for ASQoL; a 3 points change for both improvement and worsening. Defining MCID will enhance the clinical utility of ASQoL in the management of patients with axSpA

\section{REFERENCE:}

[1] Doward LC, Spoorenberg A, Cook SA, et al. Development of the ASQoL: A quality of life instrument specific to ankylosing spondylitis. Ann Rheum Dis 2003;62:20-6.

Disclosure of Interest: None declared DOI: 10.1136/annrheumdis-2018-eular.5020 